\title{
Regeneration of a recombinant infectious bursal disease virus having four amino acid substitutions in VP2 by reverse genetics
}

\author{
M Noor ${ }^{1}$, C Lüken ${ }^{2}$, PM Das', MR Islam ${ }^{1 *}$ and H Müller ${ }^{2}$ \\ Department of Pathology, Faculty of Veterinary Science, Bangladesh Agricultural \\ University, Mymensingh-2202, Bangladesh
}

\begin{abstract}
Infectious bursal disease virus (IBDV), a virus with a double-stranded, bi-segmented RNA genome, is an economically important pathogen of chickens. Recent understanding of the molecular biology of IBDV has implicated several amino acid residues in the capsid protein VP2 in pathogenicity and tissue culture adaptation. In the present study a recombinant strain of IBDV having four mutations in VP2 (Gln253His, Asp279Asn, Ala284Thr and Ser330Arg) has been generated using reverse genetics. Desired mutations were introduced in the VP2 gene of the cloned cDNA of genome segment A of a very virulent (vv) IBDV by site-directed mutagenesis. Capped RNA transcribed in vitro from cloned cDNA of the modified segment $A$ and wild type segment $B$ was co-transfected into chicken embryo fibroblast (CEF) cell culture. The recombinant virus, designated as BD$3 \mathrm{tcC}$, was rescued from the transfected cell culture and characterized in vitro. BD-3tcC retained all the four desired mutations and replicated with titres only slightly lower than those of CEF cell-culture-adapted wild-type IBDV. This recombinant strain can be used in future studies for understanding the biological significance of these four amino acid residues in VP2. (Bangl. vet. 2014. Vol. 31, No. 1, 12 - 19)
\end{abstract}

\section{Introduction}

Infectious bursal disease (IBD) or Gumboro disease is an economically important disease of poultry worldwide. It is caused by infectious bursal disease virus (IBDV) belonging to the family Birnaviridae (Dobos et al., 1979; Leong et al., 2000; Müller et al., 2003). There are two distinct serotypes of IBDV (McFerran et al., 1980). Serotype 1 strains are pathogenic and serotype 2 strains are non-pathogenic. The pathogenic serotype 1 field isolates can be further grouped into classical virulent (cv), very virulent (vv) and antigenic variant strains. The vvIBDV can cause up to $70 \%$ or even higher mortality in the field (Chettle et al., 1989; van den Berg et al., 1991). Based on comparison between wild type IBDV strains and their counterparts adapted to cell culture, four amino acid mutations (Gln253His, Asp279Asn, Ala284Thr and Ser330Arg) were identified in the VP2 capsid protein to be associated with tissue

\footnotetext{
1 Department of Pathology, Faculty of Veterinary Science, Bangladesh Agricultural University, Mymensingh-2202, Bangladesh

2 Institute for Virology, Faculty of Veterinary Medicine, University of Leipzig, 04103 Leipzig, Germany

* Corresponding author:- E-mail: mrislam_bau@yahoo.com
} 
culture adaptation (Yamaguchi et al., 1996). Subsequently, a vvIBDV was adapted in tissue culture by introducing two mutations (Gln253His and Ala284Thr) in VP2 (Lim et al., 1999). Previously, we also regenerated a recombinant IBDV strain (designated as BD-3tc) by reverse genetics after site-directed mutagenesis of these two amino acids (Gln253His and Ala284Thr) in the backbone of a vvIBDV (Islam et al., 2001b; Raue et al., 2004). The recombinant strain BD-3tc grew in chicken embryo fibroblast (CEF) cell culture and was partially attenuated for chickens, but the point mutations introduced in BD-3tc reverted during infection in chickens (Raue et al., 2004). In the present study, we rescued another recombinant IBDV strain (designated as BD-3tcC), which had the four amino acid substitutions in VP2, as originally suggested to be associated with tissue culture adaptation of IBDV (Yamaguchi et al., 1996). The rescued strain, designated as $\mathrm{BD}-3 \mathrm{tcC}$, was analysed for the presence of introduced mutations, and growth kinetics were studied in vitro in CEF cell culture.

\section{Materials and Methods}

\section{Site-directed mutagenesis and re-construction of clones}

Previously constructed full-length cDNA clones of segment $\mathrm{A}$ and segment $\mathrm{B}$ of a wild type vvIBDV (BD-3wt) in pUC19 vector (pVL561 \& pVL547) and that of a modified segment A of a recombinant IBDV strain BD-3tc (pVL565) [4, 5] were used as starting materials. All the cloned cDNA had the T7 promoter at the $5^{\prime}$ end. BD-3tc had already two amino acid substitutions at positions 253 (Gln $\rightarrow$ His) and 284 $(\mathrm{Ala} \rightarrow \mathrm{Thr}$ ) of VP2 gene. In the present study two additional amino acid substitutions at position 279 (Asp $\rightarrow$ Asn) and 330 (Ser $\rightarrow$ Arg) were introduced sequentially. The selected sites for mutagenesis with expected amino acid changes (Gln253His, Asp279Asn, Ala284Thr and Ser330Arg) are shown in Table 1.

The primers used in site-directed mutagenesis are listed in Table 2. First the mutagenic primer "IBDV-D279N" and a flanking primer "INCO-DC\#3" (Islam et al., 2001a) were used on the pVL565 (BD-3tc) template to synthesize a 405 bp megaprimer having the desired mutation (Asp279Asn). Then the synthesized megaprimer and the other flanking primer "INCO-DC\#4" were used on the same template to amplify a $677 \mathrm{bp}$ VP2 gene fragment having the desired mutation. The amplified PCR product was cloned in the pCR-2.1 plasmid vector by the TA cloning method and designated as pBAU5. To introduce a further mutation at position 330 (Ser $\rightarrow$ Arg), a $167 \mathrm{bp}$ megaprimer was synthesized with the mutagenic primer "IBDV-S330R" and the flanking primer "INCO-DC\#4" using the plasmid pBAU5 as the template. This megaprimer and the other flanking primer "INCO-DC\#3" were then used on the same template to amplify a $677 \mathrm{bp}$ VP2 gene fragment having the four mutations (Gln253His, Asp279Asn, Ala284Thr and Ser330Arg). The amplified PCR product was cloned in the pCR-2.1 plasmid vector by TA cloning and designated as pVL907. For re-construction of a full-length clone of modified segment A having four desired mutations, a 349 bp fragment was cleaved from pVL907 with ClaI and SpeI and exchanged with the corresponding region of the plasmid pVL561. The sequence of the 
re-constructed clone was checked by restriction enzyme analysis and sequencing for the presence of the desired mutations. The modified plasmid was designated as pVL 913.

\section{Regeneration and rescue of mutant virus}

The procedure for regeneration and rescuing of mutant IBDV has been described (Mundt and Vakharia, 1996; Raue et al., 2004). Full-length cloned cDNA of the modified segment A (pVL913) and the wild-type vvIBDV segment B (pVL547) (Islam et al., 2001a; 2001b) were used. In brief, cDNA corresponding to genome segments A and $\mathrm{B}$ were transcribed in vitro using $\mathrm{T} 7$ polymerase by run-off transcription method from the plasmids linearised with an appropriate enzyme. The capped RNA corresponding to segments A and B were co-transfected in chicken embryo fibroblast cells in the presence of a liposome. The expression of viral proteins in transfected cells was confirmed by immuno-fluorescence assay using a monoclonal anti-VP2 antibody (1/A6) (Becht et al., 1988) $24 \mathrm{~h}$ after transfection. The supernatant from transfected cells was further passaged in fresh CEF cell cultures and observed for the development of virus-specific cytopathic effects (CPE). The rescued recombinant virus was characterized in vitro for the presence of the desired mutations by RT-PCR followed by restriction enzyme analysis with appropriate enzymes and sequencing. The recombinant IBDV strain, regenerated and rescued in this study, having four amino acid substitutions (Gln253His, Asp279Asn, Ala284Thr and Ser330Arg) was designated as BD-3tcC.

Table 1. Selected sites for mutations with expected amino acid changes

\begin{tabular}{l|c|c|c|c|c|c}
\hline $\begin{array}{l}\text { Nucleotide } \\
\text { position in } \\
\text { Segment A }\end{array}$ & $\begin{array}{c}\text { Original } \\
\text { codon }\end{array}$ & $\begin{array}{c}\text { Mutated } \\
\text { codon }\end{array}$ & $\begin{array}{c}\text { Amino } \\
\text { acid } \\
\text { position } \\
\text { in VP2 }\end{array}$ & $\begin{array}{c}\text { Original } \\
\text { Amino } \\
\text { acid }\end{array}$ & $\begin{array}{c}\text { Exchanged } \\
\text { Amino } \\
\text { acid }\end{array}$ & Remarks \\
\hline $877-879$ & CAA & CAT $^{*}$ & 253 & Gln & His & $\begin{array}{c}\text { StuI site disappears } \\
\text { NcoI site is introduced }\end{array}$ \\
$965-967$ & GAC & AAT & 279 & Asp & Asn & - \\
$980-982$ & GCC & ACC* & 284 & Ala & Thr & NaeI site disappears \\
$1118-1120$ & AGT & CGT & 330 & Ser & Arg & $\begin{array}{c}\text { Eco 72I/PmlI site is } \\
\text { introduced }\end{array}$ \\
\hline
\end{tabular}

* Previously done in BD-3tc (Islam et al., 2001a)

In vitro growth curve and plaque morphology of mutant virus

The growth curve and plaque morphology of the newly generated recombinant strain BD-3tcC having four mutations, a previously generated recombinant strain BD-3tc having two mutations (Islam et al., 2001b), and a cell culture-adapted classical IBDV strain Cu-1 (Nick et al., 1976) were studied. Confluent CEF cell monolayers grown in Petri dishes were infected at a multiplicity of infection (m.o.i.) of 0.5. After incubation 
for $1 \mathrm{~h}$ at $38^{\circ} \mathrm{C}$ the supernatant was removed, the cells were washed twice with PBS, and fresh medium was added. At $0,4,8,16,24$ and $48 \mathrm{hr}$ after infection, cell culture supernatants from two Petri dishes each were collected and centrifuged at low speed $(400 \mathrm{~g})$ for $10 \mathrm{~min}$ and the clarified supernatant was preserved at $-20^{\circ} \mathrm{C}$ to determine extracellular virus concentration. Then $2 \mathrm{ml}$ fresh medium was added to the dishes. After 3 cycles of freezing and thawing the cell lysate was centrifuged at 3,000g for 10 min, the supernatant was collected and frozen at $-20^{\circ} \mathrm{C}$ to determine intracellular virus concentration. Virus titres in the culture supernatant and cell lysate preparation at each time point were determined by plaque assay (Nick et al., 1976; Müller et al., 1986).

Table 2. Primers used in the synthesis of megaprimers and mutated gene fragments by PCR

\begin{tabular}{|c|c|c|c|}
\hline Primer & Orientation & Sequence & $\begin{array}{l}\text { Nucleotide } \\
\text { position }\end{array}$ \\
\hline INCO-DC\#3* & Sense & 5'-AACAGCCAACATCAACG-3' & $571-587$ \\
\hline $\begin{array}{l}\text { Mutagenic } \\
\text { Primer IBDV- } \\
\text { D279N }\end{array}$ & Anti-sense & 5'-AGCCCATTaTtTGCGGCTACAGCT-3' & $975-952$ \\
\hline $\begin{array}{l}\text { Mutagenic } \\
\text { Primer IBDV- } \\
\text { S330R }\end{array}$ & Sense & 5'-GGTCAGCAcGTGGGAGCCTAGCAG-3' & $1110-1133$ \\
\hline INCO-DC\#4* & Anti-sense & 5'-GCTCGAAGTTGCTCACCC-3' & $1247-1230$ \\
\hline
\end{tabular}

NB. Mutated nucleotides are given in lower case, ${ }^{*}$ Islam et al. (2001a)

\section{Results and Discussion}

Regeneration and rescue of mutant virus

Site-directed mutagenesis was successfully accomplished to introduce the desired mutations (Table 1) in the cloned full-length cDNA of genome segment A of vvIBDV (BD-3wt). On restriction enzyme analysis of the modified clone pVL913, the disappearance of StuI and NaeI sites and introduction of NcoI and PmlI sites in the insert confirmed the desired mutations (data not shown). PCR amplification and sequencing of the cDNA fragment corresponding to the hyper-variable region of inserted VP2 gene in the plasmid pVL 913 confirmed the desired mutations.

Run-off transcription of the linearised plasmids pVL913 and pVL543 produced RNA transcripts (Fig. 1) corresponding to the modified segment $\mathrm{A}$ and wild type segment $\mathrm{B}$ of vvIBDV, respectively. Co-transfection of CEF cells with capped RNA transcripts of modified segment A cDNA, having four mutations, and wild type segment B cDNA resulted in the expression of IBDV protein in the cytoplasm as indicated by specific immuno-fluorescence observed at 24 hours after transfection (Fig. 2). The cells showed extensive necrosis at 48 and 72 hours after transfection, but it could not be ascertained whether cell death was due to non-specific effects of transfection or virusinduced cytopathic effects (CPE). However, when the supernatant of the transfected 
cells was passaged in fresh CEF cells, a clear CPE was noticed by 48 hours after infection, and RNA isolated from the culture supernatant tested positive in IBDVspecific RT-PCR. On restriction enzyme analysis the disappearance of StuI and NaeI sites and introduction of $\mathrm{NcoI}$ and PmlI sites confirmed the desired mutations. Sequencing of the RT-PCR product further confirmed the introduced mutations resulting in desired amino acid substitutions (Gln253His, Asp279Asn, Ala284Thr and Ser330Arg). Alignment of the deduced amino acid sequences of VP2 hyper-variable region of the parental strain BD-3wt, previously generated recombinant strain BD-3tc and the present recombinant strain BD-3tcC are presented in Fig. 3.
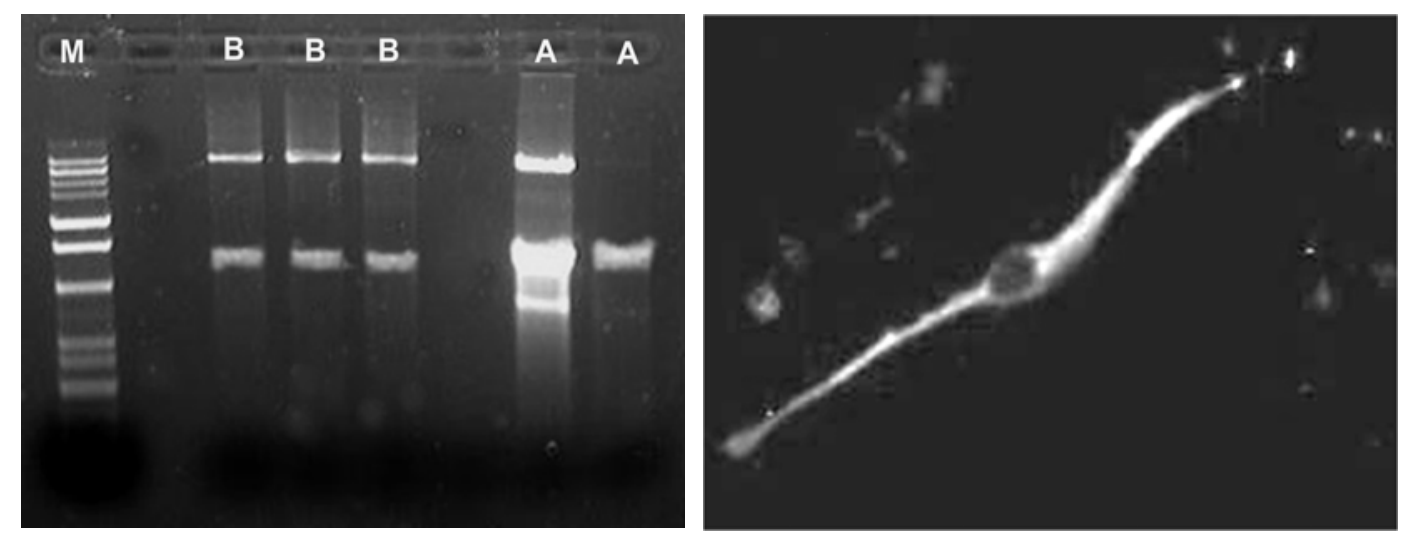

Fig. 1. RNA transcribed in vitro from the Fig. 2. Positive immuno-flurescence in CEF cells linearised plasmids with T7 RNA polymerase.

$(\mathrm{M}=$ Marker; $\mathrm{A}=\mathrm{RNA}$ corresponding to with IBDV-specific antibodies 24 hours after transfection with IBDV RNA

IBDV segment A transcribed from pVL543, B =

RNA corresponding to IBDV segment B transcribed from pVL913)

In vitro growth curve and plaque morphology of mutant virus

The growth kinetics in CEF cell culture of the recombinant IBDV strain BD-3tcC (having four mutations) is shown in Fig. 4. A previously generated recombinant IBDV strain, BD-3tc (having two mutations), and a tissue-culture-adapted classical IBDV strain $\mathrm{Cu}-1$ were included in the study for comparison. BD-3tc and BD-3tcC were used after second passage in CEF cells, while cu-1 had an unknown passage history.

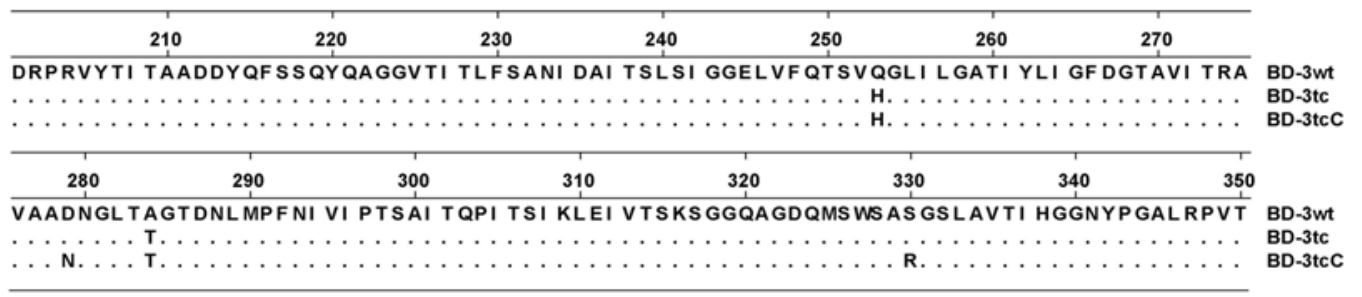

Fig. 3. Alignment of deduced amino acid sequences of VP2 (residues 201-350) of BD-3wt, BD-3tc and BD-3tcC. Residues identical to that of BD-3wt are indicated as dots. 

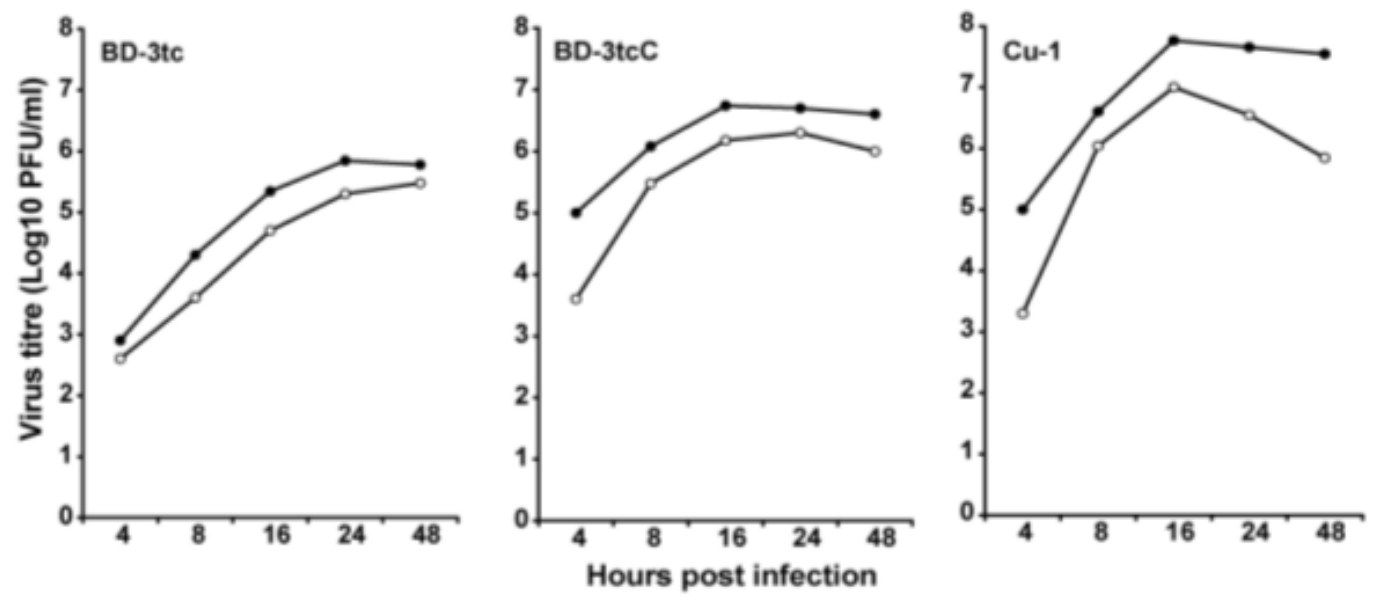

Fig. 4. Growth curves of BD-3tc, BD-3tcC and Cu-1, established as the concentration of free virus (line with closed circles) and cell-associated virus (line with open circles) after infection of CEF cells. The titres given as plaque forming units (PFU) per $\mathrm{ml}$ represent the mean of two independent experiments

All three virus strains grew in cell culture. Although the growth curve was quite similar, $\mathrm{Cu}-1$ yielded the highest amount of virus followed by BD-3tcC and BD-3tc. In each case the amount of virus in the culture supernatants was higher than in the cells. Virus replication reached its peak by 16 to 24 hours and the growth was fastest in $\mathrm{Cu}-1$ and slowest in BD-3tc.

The plaque morphology of BD-3tc and BD-3tcC was similar to that of conventional cell-culture-adapted classical virulent strain $\mathrm{Cu}-1$. However, the plaque size of BD-3tc and BD-3tcC was slightly smaller than that of $\mathrm{Cu}-1$ (Fig. 5).
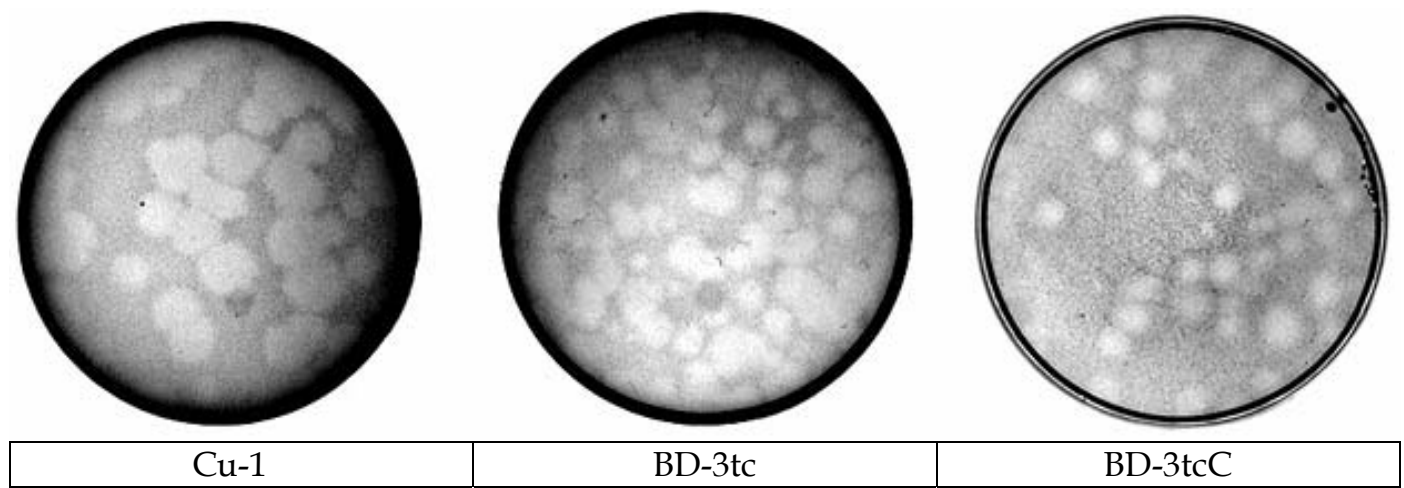

Fig. 5. Plaques in CEF cell culture produced by BD-3tc, BD-3tcC, and tissue-cultureadapted classical virulent IBDV strain $\mathrm{Cu}-1$

Reverse genetics procedure for IBDV was first described by Mundt and Vakharia (1996). Subsequently, reverse genetics and site-directed mutagenesis procedures were 
applied for generating recombinant strains of IBDV with one or two defined mutations (Lim et al., 1999; Mundt, 1999). Previously we generated a recombinant strain BD-3tc having two mutations (Gln253His and Ala284Thr) from the wild type vvIBDV BD-3wt (Islam et al., 2001b; Raue et al., 2004). In the present study a recombinant strain of IBDV, BD-3tcC, having four mutations in the capsid protein VP2 has been generated. As observed in the growth curve assay, BD-3tcC replicated in CEF cell culture similarly to that of classical cell-culture adapted-strain like $\mathrm{Cu}-1$ but more slowly, as indicated by the lower titre and smaller plaque size of BD-3tcC. The new recombinant strain BD-3tcC having four mutations appeared to be more adapted to grow in CEF cell culture than its predecessor BD-3tc having two mutations.

\section{Conclusions}

The recombinant IBDV strain BD-3tcC, in the backbone of very virulent genotype and having four defined mutations in the outer capsid protein VP2, would be a valuable asset for future investigation on the biological significance of these mutations. The protocol outlined in this paper could also be used to adapt available vaccine viruses to the current field situation through site-directed mutagenesis and reverse genetics to overcome the problems of vaccination failure due to antigenic drift in field isolates.

\section{Acknowledgements}

The study was supported by the Alexander von Humboldt Foundation through an Institutional Cooperation Project between the Bangladesh Agricultural University, Mymensingh, Bangladesh, and the University of Leipzig, Leipzig, Germany.

\section{References}

Becht H, Müller H, Müller HK 1988: Comparative studies on structural and antigenic properties of two serotypes of infectious bursal disease virus. Journal of General Virology 69 631-640.

Chettle N, Stuart JC, Wyeth PJ 1989: Outbreak of virulent infectious bursal disease in East Anglia. Veterinary Record 125 271-272.

Dobos P, Hill BJ, Hallett R, Kells DT, Becht H, Teninges D 1979: Biophysical and biochemical characterization of five animal viruses with bisegmented doublestranded RNA genomes. Journal of Virology 32 593-605.

Islam MR, Zierenberg K, Müller H 2001a: Regeneration and rescue of very virulent infectious bursal disease virus from cloned cDNA using cell culture and chicken embryo host system in combination. Bangladesh Journal of Microbiology 18 157-167. 
Islam MR, Zierenberg K, Raue R, Müller H 2001b: Molecular cloning and sequencing of a Bangladeshi strain of very virulent infectious bursal disease virus and its adaptation in tissue culture by site directed mutagenesis. Proceedings of the II. International Symposium on Infectious Bursal Disease and Chicken Anaemia, 16-20 June, 2001, Rauischholzhausen, Germany, pp. 30-39.

Jackwood DJ, Sommer-Wagner SE 2011: Amino acids contributing to antigenic drift in the infectious bursal disease Birnavirus (IBDV). Virology 409 33-37.

Leong JC, Brown D, Dobos P, Kibenge F, Ludert JE, Müller H, Mundt E, Nicholoson B 2000: Birnaviridae. In: Regenmortel MHV, Fauquet CM, Bishop DHL, Carstens EB, Estes MK, Lemon SM, Maniloff J, Mayo MA, McGeoch DJ, Pringle CR, Wickner RB (Editors), Virus Taxonomy Classification and Nomenclature of Viruses, Academic Press, New York. pp. 481-490.

Lim BL, Cao Y, Yu T, Mo CW 1999: Adaptation of very virulent infectious bursal disease virus to chicken embryonic fibroblasts by site-directed mutagenesis of residues 279 and 284 of viral coat protein VP2. Journal of Virology 73 2854-2862.

McFerran JB, McNulty MS, McKillop ER, Conner TJ, McCracken RM, Collins DS, Allan GM 1980: Isolation and serological studies with infectious bursal disease viruses from fowl, turkey and duck: demonstration of a second serotype. Avian Pathology 9 395-404.

Müller H, Lange H, Becht H 1986: Formation, characterization and interfering capacity of a small plaque mutant and of incomplete virus particles of infectious bursal disease virus. Virus Research 4 297-309.

Müller H, Islam MR, Raue R 2003: Research on infectious bursal disease - the past, the present and the future. Veterinary Microbiology 97 153-165.

Mundt E, Vakharia VN 1996: Synthetic transcripts of double-stranded Birnavirus genome are infectious. Proceedings of the National Academy of Science USA 93 11131-11136.

Mundt E 1999: Tissue culture infectivity of different strains of infectious bursal disease virus is determined by distinct amino acids in VP2. Journal of General Virology $\mathbf{8 0}$ 2067-2076.

Nick H, Cursiefen D, Becht H 1976: Structural and growth characteristics of infectious bursal disease virus. Journal of Virology 18 227-234.

Raue R, Islam MR, Islam MN, Islam KM, Badhy SC, Das PM, Müller H 2004: Reversion of molecularly engineered, partially attenuated very virulent infectious bursal disease virus during infection of commercial chickens. Avian Pathology 33 181-189.

van den Berg, TP, Gonze M, Meulemans G 1991: Acute infectious bursal disease in poultry: isolation and characterization of highly virulent strain. Avian Pathology 20 133-143.

Yamaguchi T, Ogawa M, Inoshima Y, Miyoshi M, Fukushi H, Hirai K 1996: Identification of sequence changes responsible for the attenuation of highly virulent infectious bursal disease virus. Virology 223 219-223. 